\title{
Study of Security Threats and Challenges in Internet of Things Systems
}

\author{
Rohit Chawla a, and Prof. N. K. Joshi ${ }^{b}$ \\ a,b \\ MIMT, Kota, India
}

Article History: Received: 11 January 2021; Accepted: 27 February 2021; Published online: 5 April 2021

\begin{abstract}
The interpretability and secured communication are major challenge in internet of things. The embedding of wireless device has low energy and bandwidth. The low energy and bandwidth cannot effort computational overhead and compromised with security threats. Primary the conventional cryptography algorithm is applied for generation and sharing of key for mode of communication. The conventional cryptography algorithms have several bottleneck issues related to generation of key and distribution of key. The NIST models provides the secured communication channel in the environments of mobility. Lack of integrity, confidentiality and authorization process of data transmitted over the network of internet of things used the concept of key generation and allocation. The process of key generation and authentication provides the authorization and authentication of data over the internet of things. In this paper present the review of security threats of internet of things.
\end{abstract}

Keywords: IoTs, security, NIST, key generation, authentication, attacks

\section{Introduction}

The integration of technology born the concept of internet of things. The quick improvement of Internet-ofThing (IoT) gadgets empowers the enormous combination of advancements from detecting innovation, correspondence innovation, information preparing, to distributed computing and artificial knowledge[1, 2, 3]. In this situation, sensors in the recognition layer gather information from nature and do quick handling. At that point, this information is transmitted through the system layers over the Internet to the cloud. In the cloud, information is additionally prepared by various applications[4], for instance, huge information applications or information mining applications to settle on choices or potentially to advise clients, and so forth $[5,6,7,8]$. In any case, IoT gadgets and information transmitted through multilayer systems may contain private information or discharge information; while the Internet condition uncovered security issues, for example, individual protection, digital assaults and sorted out violations[9, 10,11]. This raises the worries about the security and protection of the IoTs $[12,13,14]$. The answer for security and protection issues is to incorporate security highlights, for example, gadget identification, gadget/client verification and information encryption[15, 16, 17]. These security capacities are regularly considering the cryptographic calculations, including open key cryptography and symmetric cryptography, which involve handling force and increment power and vitality utilization[18, 19]. The present issues on security of the IoTs might be comprehended by utilizing the current accessible cryptographic natives[20]. Gadgets and conventions with appropriate utilization of identification, verification and information encryption will diminish the danger of uncovering emit or individual information to aggressors. Interestingly, symmetric cryptography including square figure and stream figure is adjusted to information encryption as a result of its quick activities[21, 22, 23]. Between two kinds of symmetric cryptography calculations, stream figures are fit for producing the encoded information stream quick, however they are restricted to just stream information encryption[24, 25, 26]. Then again, piece figures can be configured for various security capacities utilizing the task modes to be utilized as a stream figure, a square figure, or a component for validation[27, 28, 29]. It is more flexible for applications to utilize piece figures for various security purposes. Among piece figure calculations, AES is an all-around examined calculation which is generally utilized as a part of the present guidelines for IoT as well as for different applications, for example, arrange conventions, information encryption, and capacity encryption etc[30]. As of late, there has been the development of new square figure calculations that are lightweight as far as equipment or programming usage and memory impressions, yet they concoct diminished security levels. The respectability and privacy of information rely upon the security arrangement of system layers[31, 32, 33]. The rest of paper discuss as in section-II discuss the issue and challenge of IoTs. In section III discuss system model of cloud based IoTs. In section IV discuss the research goals of security and finally discuss the conclusion and future work in section V.

\section{Issue and Challenges}

The open communication models of internet of things faced a issue of security threats. The security threats of internet of things basically focus on three layers application layer, network layer and mac layer. The issue and challenges of security describe in format of tables.

\begin{tabular}{|c|c|c|c|}
\hline $\begin{array}{c}\text { Et } \\
\text { al. }\end{array}$ & Author & DESCRIPTION & ISSUES AND CHALLENGES \\
\hline
\end{tabular}




\begin{tabular}{|c|c|c|c|}
\hline [1] & $\begin{array}{l}\text { Jun Zhou, Zhenfu } \\
\text { Cao, Xiaolei Dong } \\
\text { and Athanasios V. } \\
\text { Vasilakos }\end{array}$ & $\begin{array}{ll}\text { 1. Internet of } \\
\text { Things } \\
\text { 2. Network } \\
\text { Architecture of } \\
\text { Cloud-Based } \\
\text { IoT } \\
\text { 3. Security and } \\
\text { Privacy } \\
\text { Requirements } \\
\text { for Cloud-based } \\
\text { IoT } \\
\text { 4ecure Packet } \\
\text { Forwarding in } \\
\text { Cloud-Based } \\
\text { IoT } \\
\text { Privacy- } \\
\text { Preserving } \\
\text { Authentication } \\
\text { in Cloud-Based } \\
\text { IoT }\end{array}$ & $\begin{array}{l}\text { How to design new efficient privacy- } \\
\text { preserving solutions for next generation } \\
\text { mobile technologies with IoT-cloud } \\
\text { convergence is a crucial issue of great } \\
\text { concern. } \\
\text { The first problem is fine-grained cipher-text } \\
\text { access control in cloud-based IoT. }\end{array}$ \\
\hline [2] & $\begin{array}{l}\text { Prem Prakash } \\
\text { Jayaraman, Xuechao } \\
\text { Yang, Ali Yavari, } \\
\text { Dimitrios } \\
\text { Georgakopoulos and } \\
\text { Xun Yi }\end{array}$ & 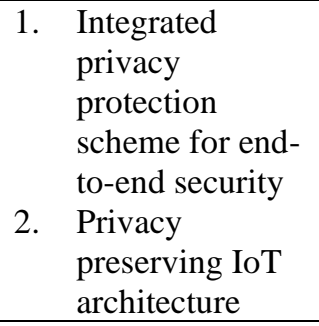 & $\begin{array}{l}\text { - The key issue is, that someone should only be } \\
\text { able to decrypt a ciphertext if the person holds } \\
\text { a key for matching attributes. User keys are } \\
\text { issued by some trusted party. } \\
\text { - We tackle the IoT privacy preservation } \\
\text { problem. }\end{array}$ \\
\hline [3] & Engin Leloglu & $\begin{array}{ll}\text { 1. } & \text { IoT Scope and } \\
\text { Architecture } \\
\text { 2. } & \text { Security of IoT }\end{array}$ & $\begin{array}{l}\text { Data security is another issue on these layers. There are } \\
\text { various precautions taken by security system on IoT such } \\
\text { as: } \\
\text { - Safe programming and anti-virus software } \\
\text { testing against malicious code injections and } \\
\text { service loopholes, } \\
\text { - Verification of data and developing temporary } \\
\text { cache against malicious operations, } \\
\text { - Session inspection mechanism to stop attacks } \\
\text { of hijacking and redo sessions, } \\
\text { Boundary inspection, data encryption } \\
\text { mechanism and resource access control to } \\
\text { avoid leakage of privacy. }\end{array}$ \\
\hline$[4]$ & $\begin{array}{l}\text { Xiruo Liu, Meiyuan } \\
\text { Zhao, Sugang Li, } \\
\text { Feixiong Zhang and } \\
\text { Wade Trappe }\end{array}$ & $\begin{array}{ll}\text { 1. } & \begin{array}{l}\text { Survey of the } \\
\text { Evolution of IoT } \\
\text { Architectures }\end{array} \\
\text { 2. } & \begin{array}{l}\text { General Security } \\
\text { Analysis of IoT } \\
\text { Systems }\end{array} \\
\text { 3. } \text { Mobility-First- } \\
\text { Based IoT } \\
\text { Architecture } \\
\text { 4oT Middleware } \\
\text { Security } \\
\text { Delegation- } \\
\text { Based Key } \\
\text { Provisioning } \\
\text { Protocol }\end{array}$ & $\begin{array}{l}\text { This paper addresses this issue by introducing } \\
\text { a unified IoT framework based on the } \\
\text { Mobility-First future Internet architecture that } \\
\text { explicitly focuses on supporting security for } \\
\text { the IoT. }\end{array}$ \\
\hline$[5]$ & $\begin{array}{l}\text { Behrouz Pourghebleh } \\
\text { and Nima Jafari } \\
\text { Navimipour }\end{array}$ & $\begin{array}{ll}\text { 1. } & \text { Related } \\
\text { terminologies } \\
\text { and basic } \\
\text { concepts } \\
\text { 2. } \\
\text { Research } \\
\text { methodology }\end{array}$ & $\begin{array}{l}\text { The important issue of the tree-based } \\
\text { mechanism is the building of an energy } \\
\text { efficient data aggregation tree. }\end{array}$ \\
\hline
\end{tabular}




\begin{tabular}{|c|c|c|c|}
\hline & & $\begin{array}{l}\text { 3. Data } \\
\text { aggregation } \\
\text { mechanisms in } \\
\text { IoT }\end{array}$ & 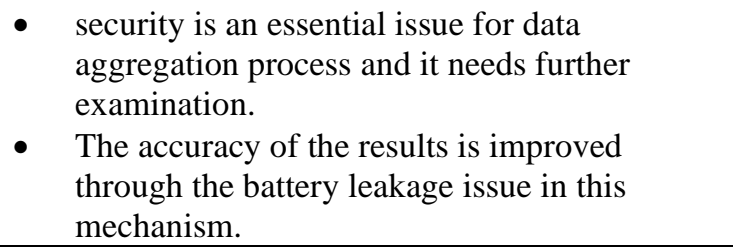 \\
\hline [6] & $\begin{array}{l}\text { Soumya Ranjan } \\
\text { Moharana, Vijay } \\
\text { Kumar Jha, Anurag } \\
\text { Satpathy, ourav Kanti } \\
\text { Addya, Ashok Kumar } \\
\text { Turuk and } \\
\text { Banshidhar Majhi }\end{array}$ & $\begin{array}{ll}\text { 1. } & \text { Preliminaries } \\
\text { 2. Proposed } \\
\text { Architecture } \\
\text { 3. Simulation } \\
\text { Results and } \\
\text { Discussion }\end{array}$ & $\begin{array}{l}\text { - The most important shortcoming of IoT cloud } \\
\text { networks which needs immediate addressing is } \\
\text { the issue of IoT nodes when used within a } \\
\text { virtual network of a cloud system. } \\
\text { The issue here is the use of same access } \\
\text { strategy across all devices making it to share a } \\
\text { common password across all other devices } \\
\text { within a network. } \\
\text { we addressed the issue of secure key- } \\
\text { distribution in IoT cloud networks thereby } \\
\text { reducing the infection between the user-groups } \\
\text { within a IoT cloud network as well as } \\
\text { managing the traffic for communication } \\
\text { among the user-groups and IoT nodes present } \\
\text { inside them. }\end{array}$ \\
\hline [7] & $\begin{array}{l}\text { Bilal Javed, Mian } \\
\text { Waseem Iqbal and } \\
\text { Haider Abbas }\end{array}$ & $\begin{array}{ll}\text { 1. } & \text { Applications of } \\
\text { IoT } \\
\text { 2. }\end{array}$ & $\begin{array}{l}\text { Embedded security becomes a key issue in IoT } \\
\text { devices which are constrained in terms of } \\
\text { processing, power, memory and bandwidth. } \\
\text { Intentional interference of GNSS signals, } \\
\text { including jamming and spoofing, is discussed } \\
\text { with a view on the legal challenges it presents. } \\
\text { Legal issues are dis-cussed on a supra-national } \\
\text { level, that is, in the framework of the } \\
\text { European Union (EU). } \\
\text { Privacy of users' location information in LBS } \\
\text { is an issue of increasing importance as more } \\
\text { and more of peoples' sensitive location } \\
\text { information gets recorded and stored into LBS. }\end{array}$ \\
\hline [8] & $\begin{array}{l}\text { Liang Chen, Sarang } \\
\text { Thombre, Kimmo Jã, } \\
\text { Rvinen, Elena } \\
\text { Simona Lohan, } \\
\text { Anette Alã Savikko, } \\
\text { Helena Leppã Koski, } \\
\text { M. Zahidul H. } \\
\text { Bhuiyan1, Shakila } \\
\text { Bu-Pasha, Giorgia } \\
\text { Nunzia Ferrara, } \\
\text { Salomon Pã,Ivi } \\
\text { Korpisaari and Heidi } \\
\text { Kuusniemi }\end{array}$ & $\begin{array}{ll}\text { 1. } & \text { Robustness and } \\
\text { security of } \\
\text { GNSS-based } \\
\text { solutions for } \\
\text { localization in } \\
\text { IoT } \\
\text { 2. Security of non- } \\
\text { GNSS solutions } \\
\text { for localization } \\
\text { 3. } \begin{array}{l}\text { Cryptographic } \\
\text { techniques for } \\
\text { secure and } \\
\text { privacy- } \\
\text { preserving } \\
\text { positioning in } \\
\text { IoT } \\
\text { Legal } \\
\text { dimensions of } \\
\text { location data } \\
\text { privacy } \\
\text { Technical and } \\
\text { legal } \\
\text { requirements } \\
\text { and } \\
\text { recommendation } \\
\text { s for trusted } \\
\text { localization } \\
\text { solutions in IoT }\end{array} \\
\end{array}$ & $\begin{array}{l}\text { - The key management problem in the defined } \\
\text { access structure. } \\
\text { Scheme is secure against possible known } \\
\text { attacks under the hardness assumption of } \\
\text { factorization of RSA modulus N = pq and } \\
\text { hardness of solving computational Diffie- } \\
\text { Hellman problem (CDHP) } \\
\text { Under the hardness of solving the integer } \\
\text { factorization problem, our scheme is secure } \\
\text { against an adversary }\end{array}$ \\
\hline
\end{tabular}




\begin{tabular}{|c|c|c|c|}
\hline [9] & $\begin{array}{l}\text { Vanga Odelu, Ashok } \\
\text { Kumar Das, } \\
\text { Muhammad Khurram } \\
\text { Khan, Kim-Kwang } \\
\text { Raymond Choo and } \\
\text { Minho Jo }\end{array}$ & $\begin{array}{l}\text { 1. } \begin{array}{l}\text { Mathematical } \\
\text { preliminaries } \\
\text { and definitions } \\
\text { 2. Key } \\
\text { management in } \\
\text { defined access } \\
\text { structure }\end{array} \\
\text { 3. Proposed CP- } \\
\text { ABE-CSKC } \\
\text { scheme } \\
\text { 4. Security analysis }\end{array}$ & $\begin{array}{l}\text { - Feasible solutions for the problem of } \\
\text { establishing a session key between a client and } \\
\text { a server in the context of the Internet of Things } \\
\text { were surveyed. } \\
\text { The Decision Diffie-Hellman (DDH) problem } \\
\text { is easy but the Computational Diffie-Hellman } \\
\text { (CDH) problem is hard. } \\
\text { The protocol uses a sequence of games under } \\
\text { the decisional Diffie-Hellman (ECDDH) } \\
\text { problem in order to proof that the protocol } \\
\text { provides secure and perfect forward secrecy } \\
\text { authentication. }\end{array}$ \\
\hline [10] & $\begin{array}{l}\text { Mohamed Amine } \\
\text { Ferrag, Leandros A. } \\
\text { Maglaras, Helge } \\
\text { Janicke, Jianmin } \\
\text { Jiang and Lei Shu }\end{array}$ & 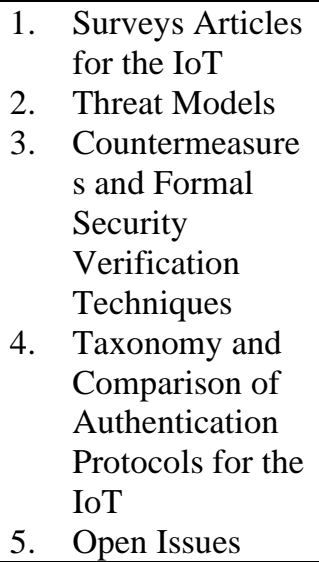 & $\begin{array}{l}\text { This special issue is intended to collect recent } \\
\text { research outcomes that address key issues and } \\
\text { topics related to self- organizing and smart } \\
\text { protocols for heterogeneous ad hoc networks } \\
\text { in the IoT. }\end{array}$ \\
\hline [11] & Tie Qiu & $\begin{array}{ll}\text { 1. } & \text { Internet of } \\
& \text { Things } \\
\text { 2. } & \text { Self-organizing } \\
\text { 3. } & \text { Smart protocols }\end{array}$ & $\begin{array}{l}\text { - IoT security concerns under the security triad } \\
\text { perspective and explores the current privacy } \\
\text { issues of IoT systems under different points of } \\
\text { view. } \\
\text { - The major security issue with NFC is that for } \\
\text { some cases it is not encrypted, i.e. to maintain } \\
\text { backward compatibility with RFID. }\end{array}$ \\
\hline [12] & $\begin{array}{l}\text { Diego Mendez, } \\
\text { Ioannis } \\
\text { Papapanagiotou and } \\
\text { Baijian Yang }\end{array}$ & 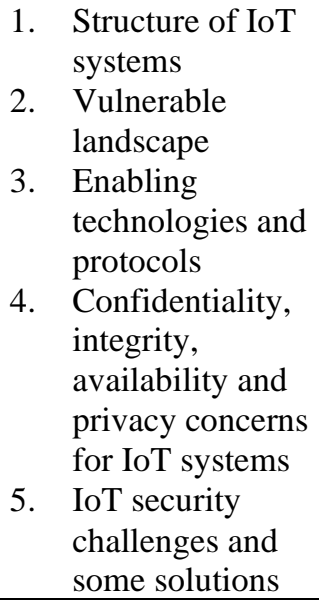 & $\begin{array}{l}\text { - Data confidentiality as a "fundamental issue" } \\
\text { for IoT solutions, "particularly relevant in the } \\
\text { business context". }\end{array}$ \\
\hline [13] & $\begin{array}{lr}\text { Martin } & \text { Henze, } \\
\text { Benedikt Wolters, } \\
\text { Roman } \quad \text { Matzutt, } \\
\text { Torsten Zimmermann } \\
\text { and Klaus They hrle }\end{array}$ & $\begin{array}{ll}\text { 1. } & \text { Controlling IoT } \\
& \text { networks } \\
\text { 2. } & \text { D-CAM design } \\
\text { 3. } & \text { Security } \\
\text { discussion } \\
\text { 4. Evaluation } \\
\text { 5. } & \text { Confidentiality } \\
\end{array}$ & $\begin{array}{l}\text { This problem is addressed, who realize fine- } \\
\text { grained access control for commands sent to } \\
\text { an IoT device. }\end{array}$ \\
\hline [14] & $\begin{array}{l}\text { Prosanta Gope, Ruhul } \\
\text { Amin, S.K. Hafizul } \\
\text { Islam, Neeraj Kumar } \\
\text { and Vinod Kumar } \\
\text { Bhalla }\end{array}$ & 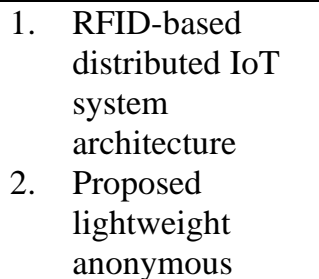 & $\begin{array}{l}\text { To address these issues, lots of anonymous } \\
\text { RFID-based authentication schemes have been } \\
\text { designed using lightweight cryptographic } \\
\text { tools, e.g., the hash function and symmetric } \\
\text { key encryption. }\end{array}$ \\
\hline
\end{tabular}




\begin{tabular}{|c|c|c|c|}
\hline & & $\begin{array}{l}\text { authentication } \\
\text { scheme } \\
\text { 3. Functionality } \\
\text { and security } \\
\text { analysis }\end{array}$ & \\
\hline [15] & $\begin{array}{l}\text { Namje Park and } \\
\text { Namhi Kang }\end{array}$ & $\begin{aligned} & \text { 1. } \text { Review of } \\
& \text { Secure IoT } \\
& \text { Environment } \\
& \text { 2. } \begin{array}{l}\text { Proposed } \\
\text { Security Scheme }\end{array} \\
& \text { 3. } \text { Service Flow of } \\
& \text { IoT Service } \\
& \text { Middleware } \\
& \text { Platform }\end{aligned}$ & $\begin{array}{l}\text { They are found to be insecure to un- } \\
\text { traceability problem, forgery attacks, de- } \\
\text { synchronization or DoS attacks. } \\
\text { pseudo-identity, one-time-alias identity and } \\
\text { track sequence number are used to resolve the } \\
\text { problem of strong anonymity, which includes } \\
\text { the anonymity and un-traceability of RFID- } \\
\text { tag. } \\
\text { This problem is avoided in the proposed } \\
\text { scheme thanks to the distributed nature of the } \\
\text { used other protocol. Finally, the proposal is } \\
\text { also resistant to identity theft because node } \\
\text { access is controlled by a strong protocol. }\end{array}$ \\
\hline [16] & $\begin{array}{l}\text { Hafsa Tahir, Ayesha } \\
\text { Kanthey } r \text { and } M . \\
\text { Junaid }\end{array}$ & 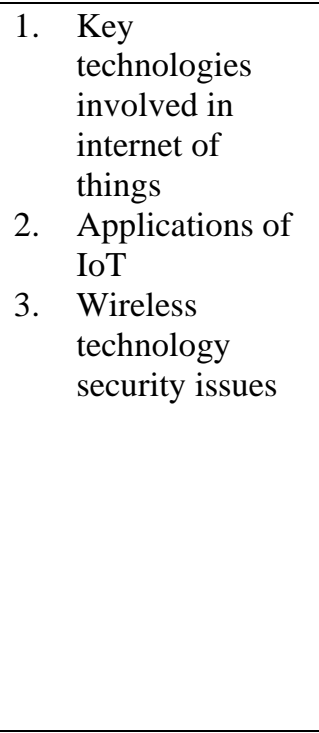 & 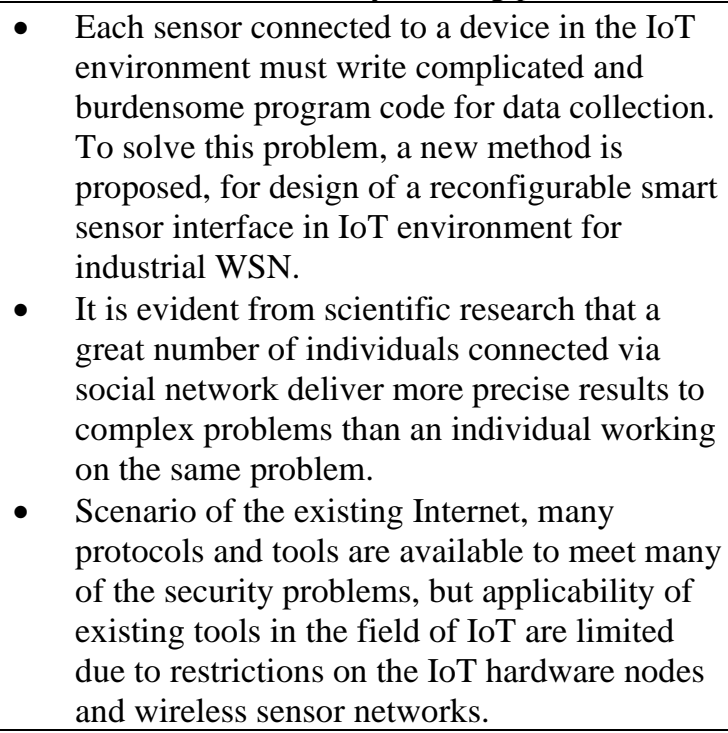 \\
\hline [17] & $\begin{array}{l}\text { Antonio L. Maia } \\
\text { Neto, Artur L. F. } \\
\text { Souza, Italo Cunha, } \\
\text { Michele Nogueira, } \\
\text { Ivan Oliveira Nunes, } \\
\text { Leonardo Cotta, } \\
\text { Nicolas Gentille, } \\
\text { Antonio A. F. } \\
\text { Loureiro, Diego F. } \\
\text { Aranha, Harsh } \\
\text { Kupwade Patil and } \\
\text { Leonardo B. Oliveira }\end{array}$ & 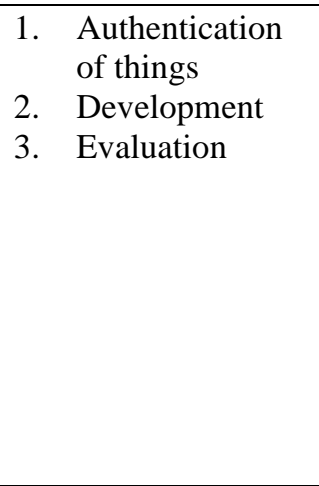 & $\begin{array}{l}\text { - This is the well-known key escrow problem of } \\
\text { identity-based systems; and the main challenge } \\
\text { for the wide adoption of IBC. } \\
\text { It has also shed some light on many long- } \\
\text { standing open problems allowing quite a few } \\
\text { of them to be solved elegantly. }\end{array}$ \\
\hline [18] & $\begin{array}{l}\text { Hokeun Kim, Armin } \\
\text { Wasicek, Benjamin } \\
\text { Mehne and Edward } \\
\text { A. Lee }\end{array}$ & $\begin{array}{l}\text { 1. } \begin{array}{l}\text { IOT security } \\
\text { requirements }\end{array} \\
\text { 2. Security } \\
\text { measures in the } \\
\text { field } \\
\text { 3. Proposed } \\
\text { approach }\end{array}$ & $\begin{array}{l}\text { The architecture provides security guarantees } \\
\text { while addressing IoT-related issues including } \\
\text { resource constraints. } \\
\text { the authentication flows cannot address some } \\
\text { of the IoT-related security and scalability } \\
\text { issues. }\end{array}$ \\
\hline [19] & $\begin{array}{l}\text { Mustafa Abdullah } \\
\text { Azzawi, Rosilah } \\
\text { Hassan and Khairul } \\
\text { Azmi Abu Bakar }\end{array}$ & $\begin{array}{l}\text { 1. Internet of } \\
\text { things for } \\
\text { healthcare } \\
\text { 2. Proposed } \\
\text { authentication } \\
\text { mechanism }\end{array}$ & $\begin{array}{l}\text { Data protection is a critical issue for networks } \\
\text { devices. In the field of IoT, security plays a } \\
\text { vital role where malicious attack or } \\
\text { interference with IoT devices can cause a } \\
\text { threat to human life especially with critical IoT } \\
\text { applications. }\end{array}$ \\
\hline
\end{tabular}




\begin{tabular}{|c|c|c|c|}
\hline [20] & $\begin{array}{l}\text { Xin Huang, Paul } \\
\text { Craig, Hangyu Lin } \\
\text { and Zheng Yan }\end{array}$ & $\begin{array}{ll}\text { 1. } & \text { IoT and security } \\
\text { requirements } \\
\text { 2. SecIoT } \\
\text { Framework } \\
\text { 3. Authentication }\end{array}$ & $\begin{array}{l}\text { - Attempts to address this problem through the } \\
\text { development of a prototype security } \\
\text { framework with robust and transparent } \\
\text { security protection. } \\
\text { The problem with having more things } \\
\text { interconnected and accessible in a 5G IoT } \\
\text { network is that there are more data available } \\
\text { with more sensors and more opportunities for } \\
\text { malicious attacks where the network can be } \\
\text { hijacked, or sensitive personal data can be } \\
\text { leaked because of inadequate security } \\
\text { protection. }\end{array}$ \\
\hline [21] & $\begin{array}{l}\text { Kai Fan, Yuanyuan } \\
\text { Gong, Chen Liang, } \\
\text { Hui Li and Yintang } \\
\text { Yang }\end{array}$ & $\begin{array}{ll}\text { 1. } & \begin{array}{l}\text { Lightweight } \\
\text { radio frequency } \\
\text { identification } \\
\text { mutual } \\
\text { authentication } \\
\text { protocol with } \\
\text { cache in the } \\
\text { reader }\end{array} \\
\text { 2. } & \text { LRMAPC } \\
\text { protocol proof } \\
\text { 3. } \begin{array}{l}\text { LRMAPC } \\
\text { evaluation }\end{array} \\
\text { 4. ULRMAPC } \\
\text { protocol }\end{array}$ & $\begin{array}{l}\text { The LRMAPC can address all the security and } \\
\text { privacy problems discussed previously, and } \\
\text { thus it achieves stronger security. }\end{array}$ \\
\hline [22] & $\begin{array}{l}\text { Lukas Malina, Jan } \\
\text { Hajny, Radek Fujdiak } \\
\text { and Jiri Hosek }\end{array}$ & $\begin{array}{l}\text { 1. } \begin{array}{l}\text { Security and } \\
\text { privacy in IoT }\end{array} \\
\text { 2. } \\
\text { Cryptographic } \\
\text { primitives and } \\
\text { schemes on } \\
\text { various devices } \\
\text { 3. Perspective of } \\
\text { privacy- } \\
\text { preserving } \\
\text { techniques in } \\
\text { internet of } \\
\text { things }\end{array}$ & $\begin{array}{l}\text { Many authentications and cryptographic } \\
\text { schemes are based on hash functions. The use } \\
\text { of such schemes that are performing many } \\
\text { hash functions or hashing the large data } \\
\text { structures (several kB) can be difficult and } \\
\text { problematic in the IoT infrastructure that } \\
\text { employs constrained devices. } \\
\text { A small RAM memory is usually problematic } \\
\text { for some security schemes that are } \\
\text { implemented on those devices. }\end{array}$ \\
\hline [23] & $\begin{array}{l}\text { Mohammed Riyadh } \\
\text { Abdmeziem, Djamel } \\
\text { Tandjaoui and Imed } \\
\text { Romdhani }\end{array}$ & 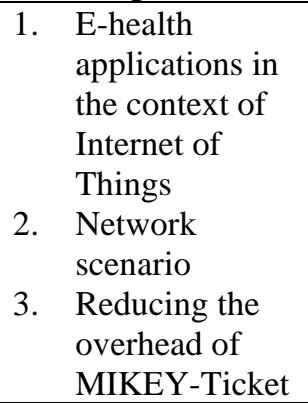 & $\begin{array}{l}\text { Classical countermeasures are not suitable to } \\
\text { the constrained environment of IoT due to } \\
\text { several factors such as power and computation } \\
\text { limitations, weak reliability of wireless links } \\
\text { and the scalability issue. } \\
\text { To overcome this issue, we have introduced } \\
\text { the use of nonce in the different exchanged } \\
\text { messages. }\end{array}$ \\
\hline [24] & $\begin{array}{l}\text { Constantinos Kolias, } \\
\text { Angelos Stavrou, } \\
\text { Jeffrey Voas, Irena } \\
\text { Bojanova } \\
\text { Richard Kuhn }\end{array}$ & 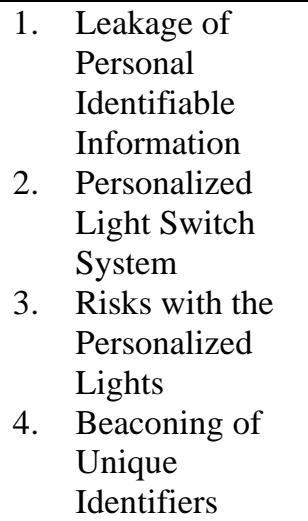 & $\begin{array}{l}\text { - } \\
\text { resource problem have been developed: } \\
\text { distributed frameworks allowing } \\
\text { geographically separated parties to cooperate } \\
\text { on testing, they are becoming available, } \\
\text { providing a full complement of shared testing } \\
\text { resources to reduce cost and testing time. }\end{array}$ \\
\hline
\end{tabular}




\begin{tabular}{|c|c|c|c|}
\hline & & 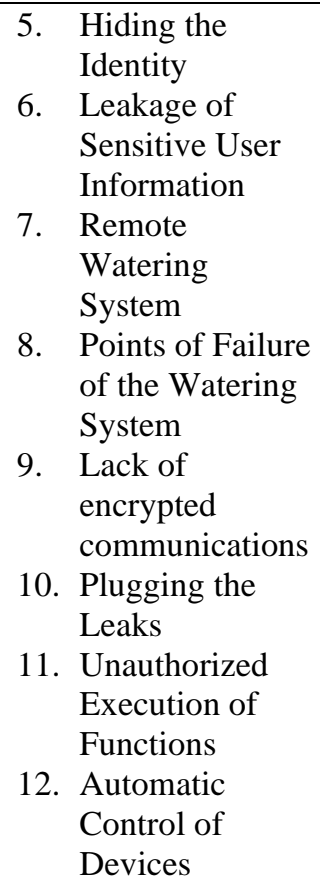 & \\
\hline [25] & $\begin{array}{l}\text { Jerker Delsing, Jens } \\
\text { Eliasson, Jan van } \\
\text { Deventer, Hasan } \\
\text { Derhamy and Pal } \\
\text { Varga }\end{array}$ & $\begin{array}{l}\text { 1. Local clouds for } \\
\text { automation }\end{array}$ & $\begin{array}{l}\text { The problems discussed are often related to } \\
\text { low level technologies e.g. protocols (CoAP, } \\
\text { 6LowPAN), or various IoT cloud concepts e.g. } \\
\text { Cumulosity, ThingWorx, Xively, Azure, } \\
\text { Websphere. } \\
\text { Automation is a key driver, the technology } \\
\text { discussions to a very large extent is addressing } \\
\text { computer science problems with little or no } \\
\text { reference to the automation requirements. }\end{array}$ \\
\hline [26] & $\begin{array}{l}\text { Er. Kritika, Dr. Harjit } \\
\text { Pal Singh, Er. } \\
\text { Narinder Pal Singh } \\
\text { and Er. Mamta }\end{array}$ & 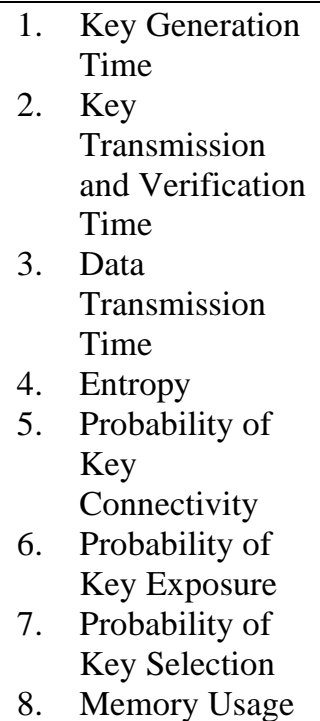 & $\begin{array}{l}\text { - Given the study on security and privacy within } \\
\text { the web of Things: Current standing and open } \\
\text { problems. As IoT systems are going to be } \\
\text { present and pervasive, variety of security and } \\
\text { privacy problems can arise. Credible, } \\
\text { economical, economical and effective security } \\
\text { and privacy for IoT area unit needed to make } \\
\text { sure precise and correct confidentiality, } \\
\text { integrity, authentication, and access } \\
\text { management, among others. }\end{array}$ \\
\hline [27] & $\begin{array}{lr}\text { Gourinath } & \text { Banda, } \\
\text { Chaitanya } & \text { Krishna } \\
\text { Bommakanti } & \text { and } \\
\text { Harsh Mohan } & \end{array}$ & $\begin{array}{ll}\text { 1. } & \text { Protocol } \\
\text { 2. } & \text { Communication } \\
\text { media } \\
\text { 3. Security } \\
\text { 4. } & \text { Message } \\
\text { structures }\end{array}$ & $\begin{array}{l}\text { They are not concerned about any potential } \\
\text { hardware specific problems of Things, they } \\
\text { experimented with simulated models of Things } \\
\text { instead of real hardware. }\end{array}$ \\
\hline [28] & $\begin{array}{l}\text { Shahid Raza, Ludwig } \\
\text { Seitz, Denis Sitenkov } \\
\text { and Goran Selander }\end{array}$ & $\begin{array}{ll}\text { 1. } & \text { S3K for } \\
\text { datagram TLS }\end{array}$ & $\begin{array}{l}\text { - Key management is one of the hardest } \\
\text { problems in cyber security. } \\
\text { It is even more challenging in the internet- } \\
\text { connected IoT considering that most things are } \\
\text { resource constrained (limited storage, } \\
\text { processing, and bandwidth). }\end{array}$ \\
\hline
\end{tabular}




\begin{tabular}{|c|c|c|c|}
\hline & & & $\begin{array}{l}\text { The problem comes from the DTLS protocol } \\
\text { specification. The DTLS state machine is } \\
\text { initialized on the Resource Server right after } \\
\text { the Client-Hello message with valid cookie is } \\
\text { received. }\end{array}$ \\
\hline [29] & $\begin{array}{l}\text { Pawani Porambage, } \\
\text { An Braeken, Pardeep } \\
\text { Kumar, Andrei } \\
\text { Gurtov and Mika } \\
\text { Ylianttila }\end{array}$ & 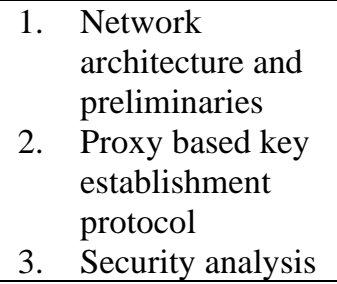 & $\begin{array}{l}\text { The lowest energy consumption at the initiator } \\
\text { node in the proxy-based solution is highly } \\
\text { acceptable for the devices with limited battery } \\
\text { life. }\end{array}$ \\
\hline [30] & $\begin{array}{l}\text { Ning Huansheng and } \\
\text { Liu Hong }\end{array}$ & $\begin{array}{l}\text { 1. The cyber- } \\
\text { physical-social- } \\
\text { thinking space } \\
\text { 2. The science and } \\
\text { technology } \\
\text { framework for } \\
\text { the IoT } \\
\text { 3. The cyber- } \\
\text { physical science } \\
\text { 4. The technology } \\
\text { framework }\end{array}$ & $\begin{array}{l}\text { - To solve practical problems during human } \\
\text { education activities based on the principle of } \\
\text { "people-oriented values". } \\
\text { - The local and indoor localization technologies } \\
\text { (e.g., RFID, and Wi-Fi) are subsequently } \\
\text { applied to address such problem. } \\
\text { Quantum computer adopts the full complexity } \\
\text { of a many-particle quantum wave function to } \\
\text { solve a computational problem, and it is } \\
\text { engineered to control the coherent quantum } \\
\text { mechanical waves with an advantage of } \\
\text { inherent parallelism }\end{array}$ \\
\hline [31] & $\begin{array}{l}\text { Kim Thuat Nguyen, } \\
\text { Maryline Laurent and } \\
\text { Nouha Oualha }\end{array}$ & $\begin{array}{l}\text { 1. } \begin{array}{l}\text { IoT security } \\
\text { overview }\end{array} \\
\text { 2. } \begin{array}{l}\text { Taxonomy of } \\
\text { security protocols } \\
\text { for the IoT }\end{array} \\
\text { 3. } \begin{array}{l}\text { Asymmetric key } \\
\text { schemes }\end{array} \\
\text { 4. Symmetric key } \\
\text { pre-distribution } \\
\text { schemes }\end{array}$ & $\begin{array}{l}\text { To deploy security solutions to this problem, } \\
\text { devices are required not only to use } \\
\text { cryptographic algorithms to perform } \\
\text { encryption. } \\
\text { Rabin's scheme is very similar to the RSA } \\
\text { algorithm, which is also based upon the } \\
\text { hardness of the factorization problem. } \\
\text { ZKP relies on some hard-mathematical } \\
\text { problems, such as the factorization of integers } \\
\text { or the discrete logarithm problem (DLP). }\end{array}$ \\
\hline [32] & $\begin{array}{l}\text { S. Sicari, A. Rizzardi, } \\
\text { L.A. Grieco and A. } \\
\text { Coen-Porisini }\end{array}$ & $\begin{array}{l}\text { 1. } \begin{array}{l}\text { IoT security } \\
\text { requirements: } \\
\text { authentication, } \\
\text { confidentiality } \\
\text { and access } \\
\text { control }\end{array} \\
\text { 2. Privacy in IoT } \\
\text { 3. Trust in IoT } \\
\text { 4. Enforcement in } \\
\text { IoT } \\
\text { 5. Secure } \\
\text { middleware's in } \\
\text { IoT } \\
\text { 6. Mobile security } \\
\text { in IoT }\end{array}$ & 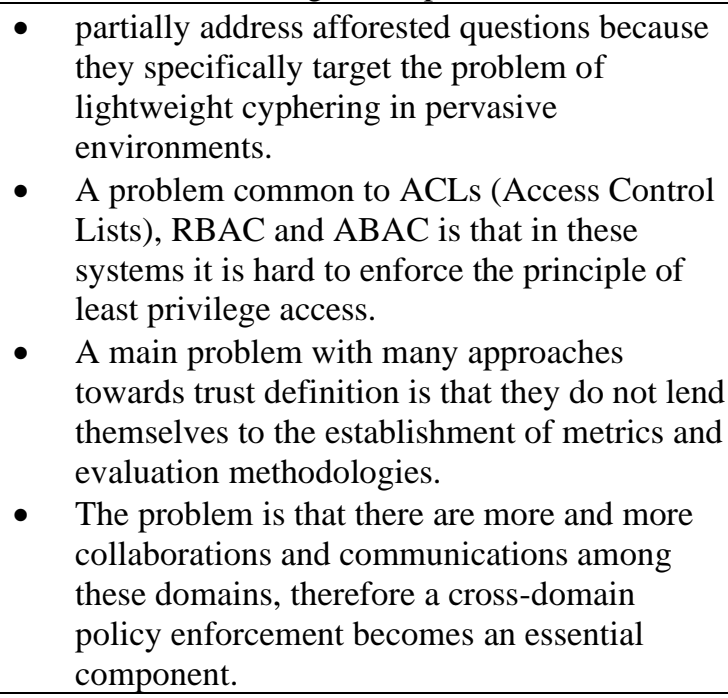 \\
\hline [33] & $\begin{array}{l}\text { Antonio Puliafito, } \\
\text { Antonio Celesti, } \\
\text { Massimo Villari and } \\
\text { Maria Fazio }\end{array}$ & $\begin{array}{ll}\text { 1. } & \text { Single and } \\
\text { Multicloud } \\
\text { Scenarios for } \\
\text { IoT } \\
\text { 2. } \\
\text { Towards Secure } \\
\text { Self- } \\
\text { Identification of } \\
\text { IoT Devices }\end{array}$ & $\begin{array}{l}\text { One of the main problems in deploying IoT } \\
\text { devices is the self-configuration of such } \\
\text { devices that is necessary to interconnect them } \\
\text { over the Cloud. } \\
\text { They examined problems in applying the } \\
\text { DTLS protocol to IoT, which comprises } \\
\text { constrained devices and constrained networks. }\end{array}$ \\
\hline
\end{tabular}




\begin{tabular}{|c|c|c|c|}
\hline & & $\begin{array}{ll}\text { 3. } & \text { An IoT Cloud- } \\
\text { Based } \\
\text { Architecture } \\
\text { 4. Registration } \\
\text { Strategies of } \\
\text { IoT Devices } \\
\text { Joining the } \\
\text { Cloud } \\
\end{array}$ & \\
\hline [34] & $\begin{array}{l}\text { Tuhin Borgohain, } \\
\text { Uday Kumar and } \\
\text { Sugata Sanyal }\end{array}$ & $\begin{array}{l}\text { Introduction to } \\
\text { OS for the IoT } \\
\text { environment } \\
\text { 2. OS'es }\end{array}$ & $\begin{array}{l}\text { - The paper introduces the various aspects of the } \\
\text { operating systems designed for the IoT } \\
\text { environment where resource constraint poses a } \\
\text { huge problem for the operation of the general } \\
\text { OS designed for the various computing } \\
\text { devices. }\end{array}$ \\
\hline [35] & $\begin{array}{l}\text { Rinju Ravindran, } \\
\text { Jerrin Yomas and } \\
\text { Jubin Sebastian E }\end{array}$ & $\begin{array}{ll}\text { 1. } & \text { Basic IoT } \\
\text { architecture } \\
\text { 2. } & \text { Protocols in IoT } \\
\text { 3. } & \text { Security issues } \\
& \text { and measures }\end{array}$ & $\begin{array}{l}\text { - It has been designed in such a way that it } \\
\text { overcomes the problems of HTTP such as high } \\
\text { computation complexity, low data rate and } \\
\text { high energy consumption. } \\
\text { Specific authentication cohesive mechanism, } \\
\text { the end-to-end authentication and key } \\
\text { agreement mechanism, PKI (Public Key } \\
\text { Infrastructure), WPKI for wireless, Security } \\
\text { routing, Intrusion detection, etc. are used to } \\
\text { tackle the security problems in the network } \\
\text { layer. }\end{array}$ \\
\hline [36] & $\begin{array}{l}\text { Sabrina Sicari, Cinzia } \\
\text { Cappiello, Francesco } \\
\text { De Pellegrini, } \\
\text { Daniele Miorandi and } \\
\text { Albertor Coen- } \\
\text { Porisini }\end{array}$ & $\begin{array}{l}\text { 1. IoT: Security } \\
\text { and data quality } \\
\text { needs } \\
\text { 2. System } \\
\text { architecture } \\
\text { 3. Application } \\
\text { case study }\end{array}$ & $\begin{array}{l}\text { They have showed that data quality problems } \\
\text { are frequent, and they should be solved or at } \\
\text { least users should be aware of the poor quality } \\
\text { of the used data sources. } \\
\text { One of the problems faced by managers of } \\
\text { retailing stores, indeed, is that they have no } \\
\text { direct access to knowledge on the behaviour of } \\
\text { users within their store. }\end{array}$ \\
\hline [37] & $\begin{array}{l}\text { Ms. R. Sujitha, Mr. N. } \\
\text { Vijaya Raghavan, } \\
\text { Ms. K. S. Suganya } \\
\text { and Prof. A. } \\
\text { Devipriya }\end{array}$ & $\begin{array}{ll}\text { 1. } & \text { Problem design } \\
\text { 2. IoT architecture } \\
\text { 3. Security of IoT } \\
\text { architecture } \\
\text { 4. Security of } \\
\text { perception layer } \\
\text { 5. Applications of } \\
\text { IoT }\end{array}$ & $\begin{array}{l}\text { The security problems of IoT system } \\
\text { technologies are grid sensor attacks, network } \\
\text { content security, unauthorized login, and } \\
\text { intrusions. } \\
\text { IoT faces other security problems such as } \\
\text { information tracking over the internet, secure } \\
\text { electronic systems, and data integrity of } \\
\text { things. }\end{array}$ \\
\hline [38] & $\begin{array}{l}\text { Jun Wu, Mianxiong } \\
\text { Dong, Kaoru Ota, } \\
\text { Jianhua Li and Bei } \\
\text { Pei }\end{array}$ & $\begin{array}{l}\text { 1. Cross-domain } \\
\text { secure access } \\
\text { scheme }\end{array}$ & $\begin{array}{l}\text { - SIoT has been studied widely. [4] focused on } \\
\text { the problem of understanding how the } \\
\text { information provided by members of the SIoT } \\
\text { must be processed to build a reliable system } \\
\text { on the basis of the behaviour of the objects. } \\
\text { fine-grained cross domain security access } \\
\text { control is one of the core problems. }\end{array}$ \\
\hline [39] & $\begin{array}{l}\text { Depeng Li, Srinivas } \\
\text { Sampalli, Zeyar } \\
\text { Aung, John Williams } \\
\text { and Abel Sanchez }\end{array}$ & $\begin{array}{l}\text { 1. SAR system } \\
\text { with } \\
\text { confidentiality } \\
\text { service } \\
\text { 2. }\end{array}$ & $\begin{array}{l}\text { - different protocols can be used to solve the IP } \\
\text { mobility problem within the aeronautical } \\
\text { environment is surveyed. }\end{array}$ \\
\hline [40] & $\begin{array}{l}\text { Qi Jing Athanasios V, } \\
\text { Vasilakos Jiafu Wan, } \\
\text { Jingtwei Lu and } \\
\text { Dechao Qiu }\end{array}$ & $\begin{array}{l}\text { 1. } \begin{array}{l}\text { Security } \\
\text { architecture of }\end{array} \\
\text { IoT } \\
\text { 2. Security issues } \\
\text { analysis of IoT } \\
\text { 3. Security issues } \\
\text { comparison } \\
\text { between IoT and }\end{array}$ & $\begin{array}{l}\text { - If IoT cannot have a good solution for security } \\
\text { issues, it will largely restrict its development. } \\
\text { Thus, above all the problems of IoT, security } \\
\text { problem is particularly important. } \\
\text { Security architecture, divide IoT into layers, } \\
\text { and sub layers, and we will extract major } \\
\text { technical supports of each sub layer, propose } \\
\text { security architecture to the problems of these } \\
\text { technologies. }\end{array}$ \\
\hline
\end{tabular}




\begin{tabular}{|c|c|c|c|}
\hline & & $\begin{array}{ll}\text { traditional } \\
\text { network } \\
\text { 4. } & \text { Open security } \\
\text { issues of IoT }\end{array}$ & \\
\hline$[41]$ & $\begin{array}{lr}\text { Zheng Yan, } & \begin{array}{r}\text { Peng } \\
\text { and }\end{array} \\
\text { Zhang } & \text { V. } \\
\text { Athanasios } & \text { Vasilakos }\end{array}$ & 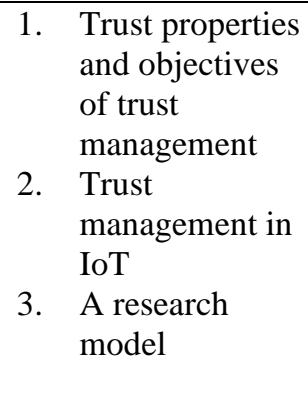 & $\begin{array}{l}\text { - Secure multi-party computation (SMC) deals } \\
\text { with the problem of secure computation } \\
\text { among participants who are not trusted with } \\
\text { each other, particularly with the preference of } \\
\text { privacy preserving computational geometry. } \\
\text { The problems of SMC are specifically } \\
\text { different in different scenarios. } \\
\text { - Secure data statistics is a specific SMC } \\
\text { problem, particularly on database query } \\
\text { privacy preservation. }\end{array}$ \\
\hline
\end{tabular}

\section{System Model of Cloud Based IoTs}

The success story of internet of things depends on the cloud network. The cloud network provides the facility of data access and data analysis[34, 35].



Figure 1 shows that the process integration of IoTs devices with cloud-based network. 


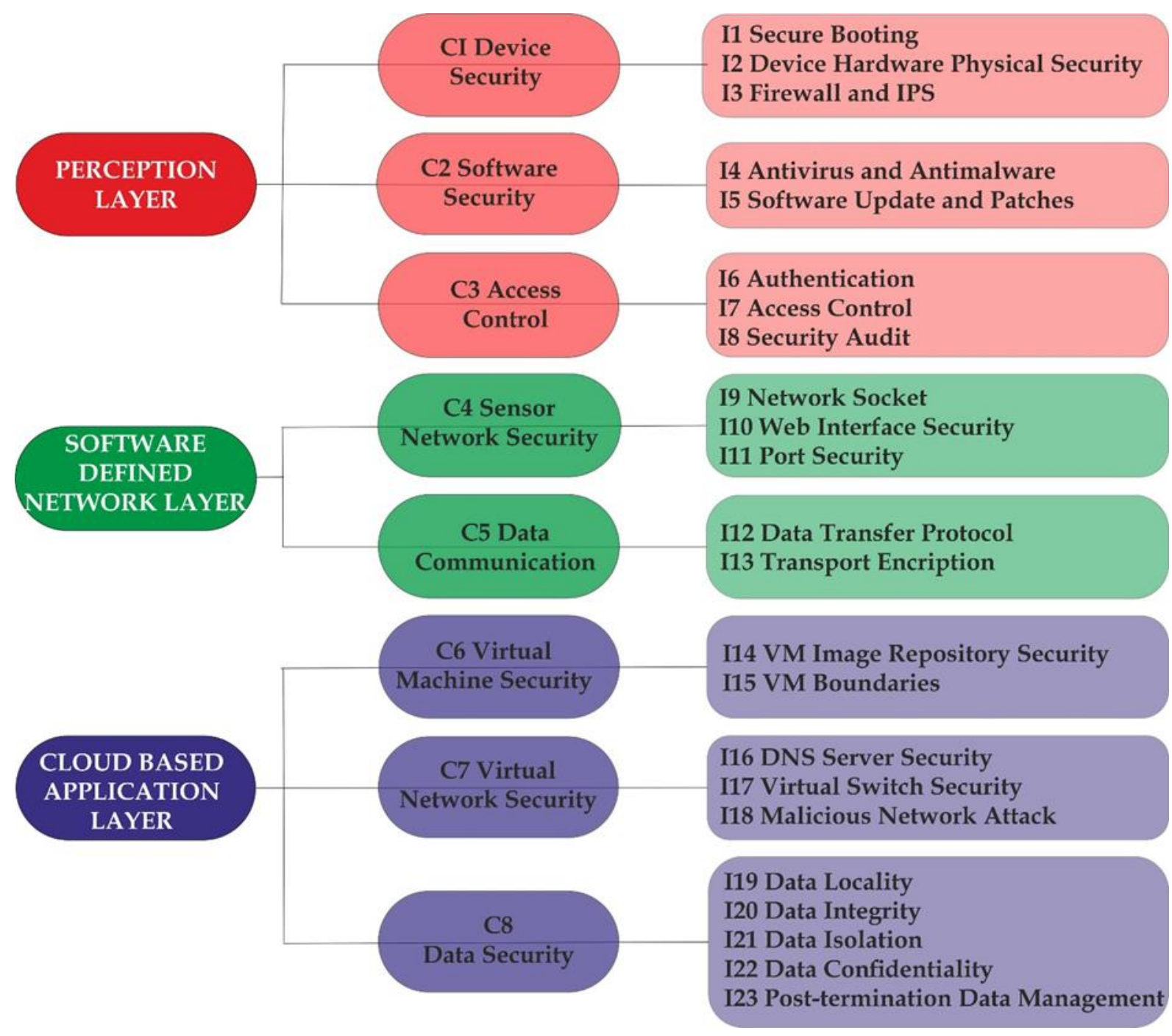

\section{Research Issue}

Figure :2 Data-security-oriented security assessment index framework

\begin{tabular}{|c|c|c|}
\hline S. No. & RESEARCH GOALS & RESEARCH RESULT \\
\hline $\mathbf{0 1}$ & Lightweight protocols & 6LoWPAN, uIP, RPL, NanoIP, TSMP \\
\hline $\mathbf{0 2}$ & Energy efficiency & $\begin{array}{l}\text { Device protocol stack focused solutions: EnOcean, LoRa, SigFox, } \\
\text { Ingenu, Weightless, DECT ULE, BLE, IEEE 802.11ah (WiFi } \\
\text { HaLow), IEEE 802.11af (White-WiFi), IEEE 802.11ba (WUR), }\end{array}$ \\
\hline $\mathbf{0 3}$ & Cognition & Bio-inspired Algorithms, Artificial Intelligence, Machine Learning \\
\hline 04 & Security & $\begin{array}{l}\text { Light weight cryptographic algorithms such as CLEFIA, } \\
\text { PRESENT, ENOCORO, TRIVIUM }\end{array}$ \\
\hline 05 & $\begin{array}{l}\text { Identification, addressing } \\
\text { and discovery }\end{array}$ & EPC, uCode, IPv6, URIs, mDSN, UPnP, Hypercat \\
\hline 06 & Data & $\begin{array}{l}\text { Concepts conclude big data analytics, cloud computing, fog } \\
\text { computing, Protocols include MQTT, CoAP, AMQP, DSS, URI }\end{array}$ \\
\hline 07 & Connectivity & $\begin{array}{l}\text { D2D networks such as IEEE } 802.11 \text { family, Bluetooth, Zigbee, Z- } \\
\text { ware. NB-IoT, Sigfox, Others include LTE-advanced, D2D in LTE, } \\
\text { ICN, SDN, NFV, CCN }\end{array}$ \\
\hline 08 & Miniaturized devices & SoC, Smart dust, Nanotechnology, NoC \\
\hline
\end{tabular}

\section{Conclusion \& Future Scope}

Security is big challenge in internet of things scenario. For the prevention of threats in scenario of internet of things used various security models. The cryptography play an important role in security concern in internet of things. The cryptography provides public and private cryptography algorithms for the generation of key for the process of authentication and authorization. The security threats is big barrier of reachability of internet of things. The IOT's based communication used collaborate and hybrid stack of protocol open stack protocol faced various challenges of security, data privacy and user authentication. Now need to provide better security protocol stack for the prevention of security and authentication of data. 


\section{References}

5. Jun Zhou, Zhenfu Cao, Xiaolei Dong and Athanasios V. Vasilakos "Security and Privacy for Cloud-Based IoT: Challenges, Countermeasures, and Future Directions”, IEEE, 2017, Pp 26-33.

6. Prem Prakash Jayaraman, Xuechao Yang, Ali Yavari, Dimitrios Georgakopoulos and Xun Yi "Privacy preserving Internet of Things: From privacy techniques to a blueprint architecture and efficient implementation”, Future Generation Computer Systems, 2017, Pp 1-10.

7. Engin Leloglu "A Review of Security Concerns in Internet of Things", Journal of Computer and Communications, 2017, Pp 121-136.

8. Xiruo Liu, Meiyuan Zhao, Sugang Li, Feixiong Zhang and Wade Trappe "A Security Framework for the Internet of Things in the Future Internet Architecture”, Future Internet, 2017, Pp 1-28.

9. Behrouz Pourghebleh and Nima Jafari Navimipour "Data aggregation mechanisms in the Internet of things: A systematic review of the literature and recommendations for future research", Journal of Network and Computer Applications, 2017, Pp 23-34.

10. Soumya Ranjan Moharana, Vijay Kumar Jha, Anurag Satpathy, ourav Kanti Addya, Ashok Kumar Turuk and Banshidhar Majhi "Secure Key-distribution in IoT Cloud Networks", IEEE, 2017, Pp 197-202.

11. Bilal Javed, Mian Waseem Iqbal and Haider Abbas "Internet of Things (IoT) Design Considerations for Developers and Manufacturers", IEEE, 2017, Pp 1-7.

12. Liang Chen, Sarang Thombre, Kimmo Jã, Rvinen, Elena Simona Lohan, Anette Alã Savikko, Helena Leppã Koski, M. Zahidul H. Bhuiyan1, Shakila Bu-Pasha, Giorgia Nunzia Ferrara, Salomon Honkala, Jenna Lindqvist, Laura Ruotsalainen, Pã,,Ivi Korpisaari and Heidi Kuusniemi “Robustness, Security and Privacy in Location-Based Services for Future IoT: A Survey”, IEEE, 2017, Pp 8956-8977.

13. Vanga Odelu, Ashok Kumar Das, Muhammad Khurram Khan, Kim-Kwang Raymond Choo and Minho Jo "Expressive CP-ABE Scheme for Mobile Devices in IoT Satisfying Constant-Size Keys and Ciphertexts”, IEEE, 2017, Pp 3273-3283.

14. Mohamed Amine Ferrag, Leandros A. Maglaras, Helge Janicke, Jianmin Jiang and Lei Shu "Authentication Protocols for Internet of Things: A Comprehensive Survey", Hindawi, 2017, Pp 1-42.

15. Tie Qiu "Self-organizing and smart protocols for heterogeneous ad hoc networks in the Internet of Things", Ad Hoc Networks, 2017, Pp 1-2.

16. Diego Mendez, Ioannis Papapanagiotou and Baijian Yang "Internet of Things: Survey on Security and Privacy", arXiv, 2017, Pp 1-16.

17. Martin Henze, Benedikt Wolters, Roman Matzutt, Torsten Zimmermann and Klaus Wehrle "Distributed Configuration, Authorization and Management in the Cloud-based Internet of Things”, IEEE, 2017, Pp 1-8.

18. Prosanta Gope, Ruhul Amin, S.K. Hafizul Islam, Neeraj Kumar and Vinod Kumar Bhalla "Lightweight and privacy-preserving RFID authentication scheme for distributed IoT infrastructure with secure localization services for smart city environment”, Future Generation Computer Systems, 2017, Pp 1-10.

19. Namje Park and Namhi Kang "Mutual Authentication Scheme in Secure Internet of Things Technology for Comfortable Lifestyle”, Sensors, 2016, Pp 1-12.

20. Hafsa Tahir, Ayesha Kanwer and M. Junaid "Internet of Things (IoT): An Overview of Applications and Security Issues Regarding Implementation”, International Journal Of Multidisciplinary Sciences And Engineering, 2016, Pp 14-22.

21. Antonio L. Maia Neto, Artur L. F. Souza, Italo Cunha, Michele Nogueira, Ivan Oliveira Nunes, Leonardo Cotta, Nicolas Gentille, Antonio A. F. Loureiro, Diego F. Aranha, Harsh Kupwade Patil and Leonardo B. Oliveira "AoT: Authentication and Access Control for the Entire IoT Device Life-Cycle”, ACM, 2016, Pp 1-15.

22. Hokeun Kim, Armin Wasicek, Benjamin Mehne and Edward A. Lee "A Secure Network Architecture for the Internet of Things Based on Local Authorization Entities”, IEEE, 2016, Pp 1-9.

23. Mustafa Abdullah Azzawi, Rosilah Hassan and Khairul Azmi Abu Bakar "A Review on Internet of Things (IoT) in Healthcare”, International Journal of Applied Engineering Research, 2016, Pp 10216-10221.

24. Xin Huang, Paul Craig, Hangyu Lin and Zheng Yan "SecIoT: a security framework for the Internet of Things", Security and Communication Networks, 2015, Pp 3083-3094.

25. Kai Fan, Yuanyuan Gong, Chen Liang, Hui Li and Yintang Yang "Lightweight and ultralightweight RFID mutual authentication protocol with cache in the reader for IoT in $5 G$ ”, security and communication networks, 2015, Pp 3095-3104.

26. Lukas Malina, Jan Hajny, Radek Fujdiak and Jiri Hosek "On perspective of security and privacypreserving solutions in the internet of things", Computer Networks, 2016, Pp 83-95.

27. Mohammed Riyadh Abdmeziem, Djamel Tandjaoui and Imed Romdhani "Lightweighted and EnergyAware MIKEY-Ticket For E-Health Applications in the Context of Internet of Things", HAL, 2017, Pp 122.

28. Constantinos Kolias, Angelos Stavrou, Jeffrey Voas, Irena Bojanova and Richard Kuhn "Learning Internet of Things Security Hands-on”, IEEE, 2016, Pp 1-17. 
29. Jerker Delsing, Jens Eliasson, Jan van Deventer, Hasan Derhamy and Pal Varga "Enabling IoT automation using local clouds", IEEE, 2016, Pp 1-6.

30. Er. Kritika, Dr. Harjit Pal Singh, Er. Narinder Pal Singh and Er. Mamta "Multivariate Authentication and Encryption Scheme for Data Privacy in IoT Healthcare Monitoring”, Imperial Journal of Interdisciplinary Research, 2016, Pp 543-550.

31. Gourinath Banda, Chaitanya Krishna Bommakanti and Harsh Mohan "One IoT: an IoT protocol and framework for OEMs to make IoT-enabled devices forward compatible”, J Reliable Intell. Environ. 2016, Pp 131-144.

32. Shahid Raza, Ludwig Seitz, Denis Sitenkov and Goran Selander "S3K: Scalable Security with Symmetric Keys -DTLS Key Establishment for the Internet of Things”, arXiv, 2016, Pp 1-11.

33. Pawani Porambage, An Braeken, Pardeep Kumar, Andrei Gurtov and Mika Ylianttila "Proxy-based Endto-End Key Establishment Protocol for the Internet of Things", ICCW, 2015, Pp 1-6.

34. Ning Huansheng and Liu Hong "Cyber-physical-social-thinking space-based science and technology framework for the Internet of Things”, Science China, 2015, Pp 1-19.

35. Kim Thuat Nguyen, Maryline Laurent and Nouha Oualha "Survey on secure communication protocols for the Internet of Things", Ad Hoc Networks, 2015, Pp 17-31.

36. S. Sicari, A. Rizzardi, L.A. Grieco and A. Coen-Porisini "Security, privacy and trust in Internet of Things: The road ahead”, Computer Networks, 2015, Pp 146-164.

37. Antonio Puliafito, Antonio Celesti, Massimo Villari and Maria Fazio "Towards the Integration between IoT and Cloud Computing: An Approach for the Secure Self-Configuration of Embedded Devices”, Hindawi Publishing Corporation, 2015, Pp 1-9.

38. Tuhin Borgohain, Uday Kumar and Sugata Sanyal "Survey of Operating Systems for the IoT Environment", arXiv, 2015, Pp 1-5.

39. Rinju Ravindran, Jerrin Yomas and Jubin Sebastian E "IoT: A Review On Security Issues And Measures”, Engineering Science and Technology: An International Journal, 2015, Pp 348-351. 